Published in final edited form as:

Pediatrics. 2018 October ; 142(Suppl 2): S72-S81. doi:10.1542/peds.2018-0333I.

\title{
Cardiac Management of the Patient With Duchenne Muscular Dystrophy
}

\author{
Sujatha Buddhe, MBBS, MS ${ }^{a}$, Linda Cripe, MD $^{b, c}$, Joshua Friedland-Little, MDa, Naomi \\ Kertesz, MD $^{\mathrm{b}, \mathrm{c}}$, Pirooz Eghtesady, MD, PhD ${ }^{\mathrm{d}}$, Jonathan Finder, $\mathbf{M D}^{\mathrm{e}}$, Kan Hor, $\mathbf{M D}^{\mathrm{b}, \mathrm{c}}$, Daniel \\ P. Judge, MD $^{f}$, Kathi Kinnett, MSN, CNPg, Elizabeth M. McNally, MD, PhD $^{h}$, Subha Raman, \\ MD, MSEE ${ }^{C}$, W. Reid Thompson, MD', Kathryn R. Wagner, MD, PhD', and Aaron K. Olson, \\ $M D^{\mathrm{a}}$
}

aSeattle Children's Hospital and School of Medicine, University of Washington, Seattle, Washington; bNationwide Children's Hospital, Columbus, Ohio; 'The Ohio State University, Columbus, Ohio; dSt Louis Children's Hospital and School of Medicine, Washington University, St Louis, Missouri; ' Children's Hospital of Pittsburgh and School of Medicine, University of Pittsburgh, Pittsburgh, Pennsylvania; ${ }^{f}$ Medical University of South Carolina, Charleston, South Carolina; 9Parent Project Muscular Dystrophy, Hackensack, New Jersey; hFeinberg School of Medicine, Northwestern University, Chicago, Illinois; 'Johns Hopkins Hospital, Baltimore, Maryland; jKennedy Krieger institute, School of Medicine, Johns Hopkins University, Baltimore, Maryland

\begin{abstract}
Duchenne muscular dystrophy (DMD) results in a progressive cardiomyopathy that produces significant morbidity and mortality. To improve the quality of life in patients with DMD, cardiac care is focused on surveillance and management, with the goal of slowing the onset and progression of heart failure complications. The current article is intended to be an expanded review on the cardiac management data used to inform the 2018 DMD Care Considerations recommendations as well as be a discussion on clinical controversies and future management directions. The new cardiac guidance includes changes regarding noninvasive imaging surveillance of cardiac function and pharmacologic therapy. Many emerging therapies lack sufficient evidence-
\end{abstract}

\footnotetext{
Address correspondence to Aaron K. Olson, MD, Seattle Children's Hospital, University of Washington, 4800 Sand Point Way NE, Seattle, WA 98105. aaron. olson@ seattlechildrens.org.

Dr Cripe served as chairperson for the Duchenne Muscular Dystrophy Care Considerations Cardiology Management Working Group convened by the Centers for Disease Control and Prevention, drafted the initial outline for the manuscript, drafted sections of the manuscript, and reviewed and revised the manuscript; Dr Olson served as cochairperson for the Duchenne Muscular Dystrophy Care Considerations Cardiology Management Working Group convened by the Centers for Disease Control and Prevention, drafted the initial outline for the manuscript, drafted sections of the manuscript, and reviewed and revised the manuscript; Ms Buddhe served on the Duchenne Muscular Dystrophy Care Considerations Cardiology Management Working Group convened by the Centers for Disease Control and Prevention, contributed to the development of corresponding recommendations, drafted the initial outline for the manuscript, drafted sections of the manuscript, and reviewed and revised the manuscript; Drs Friedland-Little and Kertesz served on the Duchenne Muscular Dystrophy Care Considerations Cardiology Management Working Group convened by the Centers for Disease Control and Prevention, contributed to the development of corresponding recommendations, drafted sections of the manuscript, and reviewed and revised the manuscript; Drs Eghtesady, Finder, Hor, Judge, McNally, Raman, Thompson, and Wagner and Ms Kinnett served on the Duchenne Muscular Dystrophy Care Consideration Cardiology Management Working Group convened by the Centers for Disease Control and Prevention, contributed to the development of corresponding recommendations, and reviewed and revised the manuscript; and all authors approved the final manuscript as submitted and agree to be accountable for all aspects of the work.
}

FINANCIAL DISCLOSURE: The authors have indicated they have no financial relationships relevant to this article to disclose. 
based data to be recommended in the 2018 DMD Care Considerations. These are discussed in the present article as clinical controversies and future directions. Important emerging therapies include new heart failure medications, mechanical circulatory support with ventricular assist devices, heart transplantation, and internal cardiac defibrillators. Future research studies should be focused on the risks and benefits of these advanced therapies in patients with DMD. We conclude this review with a brief discussion on the relationship between the heart and the recently developed medications that are used to directly target the absence of dystrophin in DMD.

The loss of dystrophin in Duchenne muscular dystrophy (DMD) results in a progressive skeletal myopathy as well as a cardiomyopathy. ${ }^{1,2}$ As cardiac function worsens, clinical heart failure develops. Improved care in other specialties, especially respiratory support, has positioned cardiomyopathy as a principal source of morbidity and mortality. ${ }^{3-7}$

The patient who is nonambulatory makes the identification of traditional heart failure symptoms challenging. Thus, regular cardiac evaluations are the core tenet for care guidelines, including the 2018 DMD Care Considerations sponsored by the Centers for Disease Control and Prevention. ${ }^{8}$ The goal is to identify early myocardial changes and initiate therapy to favorably affect ventricular remodeling, thus improving cardiac outcomes and quality of life. ${ }^{9-11}$ Unfortunately, the importance of cardiac surveillance is underappreciated in the care of the patient with DMD, as demonstrated in a recent natural history study in which researchers looked at the use of noninvasive imaging in DMD. ${ }^{12}$ Recommendations for optimal cardiac care are clearly outlined in recent care guidelines. ${ }^{8,13}$

In this companion article, we review the data and thought processes used to inform the important changes included in the 2018 DMD Care Considerations (see Fig 1 for an overview of the recommended assessments and interventions organized by stage of disease). ${ }^{8}$ Changes in imaging surveillance and recommendations regarding pharmacologic therapy will be discussed. The use of implantable defibrillators and mechanical circulatory support (ventricular assist devices) as well as heart transplantation are addressed. We conclude this review with a brief but important discussion on emerging therapies that are used to directly target the absence of dystrophin in DMD. This article is not intended to be a complete review of cardiac issues in DMD. The interested reader is referred to many excellent recent reviews. ${ }^{14-16}$

\section{CORE CHANGES}

Early diagnosis and treatment of cardiomyopathy leads to favorable ventricular remodeling in patients with DMD, ${ }^{9-11}$ which is expected to maximize the duration and quality of life. The 2018 DMD Care Considerations reaffirmed that regular cardiac evaluations are an essential foundation of DMD care. In the updated guidance, the need for cardiac assessment at the time of diagnosis is emphasized. This initial cardiac visit should include a past and present cardiac medical and family history. In addition, the clinician should perform a physical examination, electrocardiogram, and noninvasive imaging with either an echocardiogram or cardiac MRI (CMRI) on the basis of the child's age and ability to cooperate. In previous guidelines, cardiac visits were recommended every 2 years before age 10 years, and at least a yearly evaluation was recommended thereafter depending on the 
presence of ventricular dysfunction. Because of a growing recognition that adverse myocardial changes occur before overt cardiac dysfunction and at a younger age than previously thought, it is now recommended in the 2018 DMD Care Considerations that yearly cardiac screening begins at diagnosis. For patients with established cardiac abnormalities, more frequent visits may be needed.

\section{Noninvasive Imaging to Assess Cardiac Function}

Because traditional heart failure symptoms are difficult to identify in the patient with DMD who is nonambulatory, noninvasive imaging to assess cardiac function is an integral part of the cardiac evaluation. In the update, CMRI is recommended as the preferred noninvasive imaging modality for patients with DMD for reasons provided below. Echocardiography has historically been the primary imaging modality. In some patients with DMD, a significant limitation with echocardiography is inadequate acoustic imaging windows, secondary to body habitus. ${ }^{17,18} \mathrm{CMRI}$ image quality is less affected by body habitus, and multiple studies have revealed that CMRI is superior to echocardiography for diagnosing DMD-related ventricular dysfunction. ${ }^{19-21}$ Soslow et al ${ }^{19}$ found that echocardiographic image quality was suboptimal in approximately half of patients with DMD. Suboptimal echocardiographic image quality frequently causes a significant over- or underestimate of left ventricular systolic function compared with CMRI. ${ }^{20}$ Buddhe et $\mathrm{al}^{21}$ showed that an echocardiographybased ventricular functional assessment had a weak correlation with CMRI measurements, even in patients with adequate echocardiographic image quality. These studies reveal that CMRI is superior to an echocardiogram for detecting ventricular dysfunction, especially when echocardiographic scanning windows are suboptimal.

Histopathologic studies in DMD reveal subepicardial myocardial fibrosis, degeneration, and fatty infiltration. ${ }^{22,23}$ In addition to improved image quality, CMRI can detect fibrosis before changes in standard functional measurements (ie, ejection fraction [EF] and/or fractional shortening) occur. ${ }^{24}$ Gadolinium-based contrast agents used in CMRI allow for the noninvasive assessment of pathologic myocardial fibrosis by the extent of late gadolinium enhancement (LGE). ${ }^{24-26}$ The time course and distribution of this LGE positivity within the myocardium may be an important clinical biomarker to aid in the management of DMDassociated cardiac disease. ${ }^{27}$ Also, myocardial fibrosis detected by CMRI can be an independent predictor of adverse cardiac remodeling, ventricular arrhythmias, death, or a need for a cardiac transplant in DMD. ${ }^{28,29}$ Serial studies are thus warranted to determine if early medical management is useful in preventing the progression of ventricular dysfunction once LGE is documented.

Fibrotic changes in the myocardium in patients with DMD usually have a heterogeneous distribution, leading to regional wall motion abnormalities. Strain imaging, a relatively new technique that is used to quantify regional tissue deformation, improves the detection of regional wall motion abnormalities both by echocardiography and CMRI. However, an echocardiographic strain is sometimes limited by inadequate image quality. CMRI strain has better correlation with CMRI left ventricular ejection fraction (LVEF) than echocardiographic strain. ${ }^{21}$ Strain imaging analysis by CMRI tissue tagging is sufficiently sensitive to diagnose occult regional cardiac dysfunction. ${ }^{30} \mathrm{Hor}$ et al ${ }^{31}$ compared a novel 
CMRI feature tracking-based assessment of peak average circumferential myocardial strain with peak average circumferential myocardial strain derived from tagged images and found high correlation in a large population of patients with DMD who had a wide range of cardiac dysfunction. Unlike tissue tagging, a feature-tracking analysis can be performed on routine images without additional scanning. ${ }^{31}$ Increased DMD heart disease severity was found to be associated with a reduced composite of CMRI-measured circumferential strain, diminished regional circumferential strain heterogeneity, and positive LGE imaging. ${ }^{32}$ Circumferential strain in particular has qualified as the most robust parameter with the best agreement when different vendors for CMRI feature-tracking strain assessment were compared. ${ }^{33}$ Previous studies have consistently revealed that myocardial strain abnormalities are prevalent in young patients with DMD despite a normal EF, and these strain values continue to decline with advancing age. Also, a reduction in strain may precede fibrosis detected by LGE and is thus an attractive early biomarker of dysfunction, particularly because it can be detected by echocardiography. Thus, strain analysis in combination with standard echocardiography, CMRI, and LGE imaging has the potential to provide a means to risk stratify DMD cardiomyopathy. ${ }^{34}$

Clinical Controversy-Transthoracic echocardiograms remain appropriate and useful in certain clinical situations. CMRI may not be feasible because of limitations, including cost, availability, required expertise, patient discomfort secondary to contractures and body positioning, and the need for sedation in some patients. This is particularly true in children with developmental delay, claustrophobia, or who are at younger ages. Echocardiograms are also preferred when urgent results are needed, such as in the emergency department or critical care unit.

In recent reports, researchers identified gadolinium deposition in brains after multiple administrations of gadolinium-based contrast agents. ${ }^{35,36}$ The clinical significance of this is unclear; however, an adverse effect has not been established in any studies. Newer gadolinium agents may have less deposition. Further research is needed to define the incidence and significance of these gadolinium depositions. ${ }^{37}$

Future Directions-The ultimate goal is to find the most reliable, sensitive, and specific indicator of early myocardial involvement in DMD. In future studies, researchers should continue to evaluate novel imaging techniques for detecting subtle early myocardial abnormalities. T1 mapping by CMRI, a technique for assessing extracellular volume, was found to be abnormal in patients with DMD compared with that in controls (even in patients with DMD who otherwise had normal CMRIs). ${ }^{38} \mathrm{~T} 1$ mapping can be used to identify diffuse fibrosis in the myocardium (unlike LGE, which detects focal lesions). Myocardial T1 mapping and extracellular volume are examples of emerging imaging techniques in DMDrelated cardiomyopathy that may eventually become a standard of care ${ }^{39,40}$ Prospective longitudinal studies that link early CMRI changes to long-term clinical outcomes are necessary to determine which established and/or novel CMRI techniques are most important for DMD-related clinical management. This information could also be extremely important in future clinical trials. Finally, in agreement with the 2014 National Institutes of Health Working Group, ${ }^{15}$ clinical trials for DMD muscle therapies should include CMRI as the 
primary measure of cardiac safety monitoring and therapeutic efficacy rather than primarily echocardiograms.

\section{Medical Management}

Given the lack of specific therapies for DMD-related cardiomyopathy, the 2018 DMD Care Considerations endorse following traditional heart failure treatment strategies, as delineated previously and by other committees. ${ }^{13,15,41}$ Briefly, first-line therapy is angiotensinconverting enzyme inhibitors (ACEis) or angiotensin receptor blockers (ARBs). Recent studies revealed that combination therapy with the mineralocorticoid receptor antagonist eplerenone and an ACEi versus an ACEi alone in patients with DMD lessoned the decline in left ventricular function after 2 years. ${ }^{42,43}$ Thus, consideration may be given for including mineralocorticoid receptor antagonists in first-line therapy with monitoring of kidney function and blood chemistry, $\beta$-adrenergic blockers are typically added with continued ventricular dysfunction or elevated heart rates. Additional medications, such as diuretics or digoxin, should be considered in situations in which additional heart failure therapy is required. It should be noted that patients with DMD often have low systolic blood pressure, which limits the uptitration of heart failure medications.

Additional research is needed to establish optimal cardiac pharmacotherapy in DMD, including research on issues such as timing for initiating medications (discussed below), appropriate dosing, specific indications for adding additional medications, and the utility of new heart failure medications (discussed below). However, performing robust cardiac clinical trials in patients with DMD is challenging. Adult heart failure studies (non-DMD) have large patient numbers, with a relatively high incidence of clinical heart failure events (ie, hospitalizations or changes in heart failure functional classes) and mortality. In contrast, DMD is a relatively rare disorder with a long delay (possibly decades) between the onset of cardiac functional changes and mortality. Cardiac-related morbidity is also difficult to assess in DMD because of the nonambulatory status of older patients and the involvement of other organ systems. Thus, patients with DMD do not fit in traditional heart failure functional classes. This leaves noninvasive imaging measures of cardiac function to inform the benefit in most DMD cardiac trials.

Clinical Controversy-Controversy exists regarding the age to start heart failure medications in patients with DMD who have a normal cardiac evaluation, including imaging. A consensus exists for initiating medications with symptoms of heart failure, ventricular dysfunction on imaging, myocardial fibrosis (LGE on CMRI), or abnormal chamber size. The 2014 National Institutes of Health Working Group recommended that all patients with DMD start an ACEi or ARBs by age 10 years on the basis of work by Duboc et al. ${ }^{15,44,45}$ In their randomized, double-blinded, placebo-controlled study, patients with DMD between the ages of 9.5 and 13 years (mean \pm SD: $10.7 \pm 1.2$ years) with a normal LVEF $(>55 \%$ ) by echocardiogram were randomly assigned to 3 years of the ACEi perindopril or a placebo. After 3 years, all patients received open-label perindopril. Although cardiac function was similar after 3 years, the early perindopril group had fewer patients with significantly decreased ventricular function (EF of $<45 \%$ ) after 5 years and reduced mortality at 10 years.44,45 In the 2018 DMD Care Considerations, it was agreed that these 
results were sufficiently compelling to recommend starting an ACEi or ARB around age 10 years in patients with a normal cardiac evaluation. ACEis and ARBs are generally welltolerated, so some families and providers may decide to start medications before age 10 years.

Future Directions-The Food and Drug Administration recently approved 2 new classes of heart failure medications. ${ }^{46,47}$ Sacubitril/valsartan is a combination drug containing a first-in-class neprilysin inhibitor (sacubitril) and a previously approved ARB (valsartan). Compared with standard treatment with an ACEi, sacubitril/valsartan significantly reduced the composite end point of death and heart failure hospitalizations in adult patients with heart failure. ${ }^{46,48}$ A second newly approved medication is ivabradine, which is used to target the sinoatrial node to reduce heart rate. Ivabradine is recommended for patients with heart failure who have a heart rate of $>70$ beats per minute despite optimal $\beta$-adrenergic blocker usage. ${ }^{49}$ Neither sacubitril/valsartan nor ivabradine has been evaluated in patients with DMD. These new medications have a theoretical benefit for DMD but are costly, so insurance companies may be unwilling to cover the higher costs unless a benefit in DMD is demonstrated.

\section{Heart Transplant and Mechanical Circulatory Support}

Guidelines for treating severe heart failure in non-DMD cardiomyopathy include indications for medical devices (such as internal cardiac defibrillators and mechanical circulatory support) and heart transplantation. A paucity of information regarding the use of these advanced therapies in patients with DMD prevents specific recommendations for their use in DMD-related cardiomyopathy. It is clear, however, that these therapies are emerging therapeutic considerations.

Heart transplantation is the standard of care for patients with refractory end-stage heart failure. ${ }^{50}$ Given the scarcity of donor organs, however, a consensus exists among the transplantation community that to be a candidate for a heart transplant, a patient must have a reasonable chance to achieve a significant survival benefit from the transplanted heart. Heart transplantation is not considered an effective therapy in the setting of irreversible dysfunction of other organ systems. ${ }^{51}$ Some reports reveal good outcomes after a heart transplant in patients with muscular dystrophy. ${ }^{52,53}$ However, in most cases, the degree of respiratory insufficiency and muscular weakness generally found in patients with DMD who have developed severe myocardial dysfunction is thought to be a contraindication to a transplant because of the high associated risk of posttransplant mortality. ${ }^{54}$

In the adult heart failure population, mechanical circulatory support with a left ventricular assist device (LVAD) as a destination therapy (rather than as a bridge to transplantation) is now an accepted strategy to provide survival and quality-of-life benefits to patients with advanced heart failure who are not candidates for a heart transplant. ${ }^{55}$ The use of LVADs for destination therapy has grown considerably over the past decade, ${ }^{56}$ and destination therapy is currently the indication for $>45 \%$ of LVADs implanted in adult patients. ${ }^{57}$ The pediatric heart failure community has been slower to adopt the concept of destination LVAD therapy, likely in part because of concerns regarding the disparity between optimistic estimates of 
survival on an LVAD and what would be considered a normal life expectancy for a child. ${ }^{58}$ However, recent case reports of LVADs placed as a destination therapy in patients with DMD have revealed some favorable early outcomes. ${ }^{59-62}$

Clinical Controversy-Identifying patients with DMD who will achieve a real benefit from LVAD placement remains a challenge. In a recent registry analysis, $\sim 30 \%$ of adult patients who receive a destination LVAD were found to have a poor outcome, which was defined as either mortality or persistently poor quality of life at 1 year after device placement. ${ }^{63}$ Decreased functional status pre-LVAD implant was associated with an increased likelihood of poor outcome after implant in this analysis by Arnoldet al, ${ }^{63}$ and numerous earlier studies have likewise revealed a correlation between pre-LVAD health status and post-LVAD survival. ${ }^{64,65}$ In the reports of destination LVAD placement in patients with DMD, the authors emphasize the postoperative challenges posed by the respiratory insufficiency, muscle weakness and wasting, and an increased risk of bleeding found in this population. ${ }^{58,59,61,62}$ Despite improvements in device design, adverse events remain a concern for all patients on an LVAD, with bleeding, infection, and stroke being important causes of morbidity and mortality. ${ }^{57}$ The balance of risks versus benefit may shift considerably on the basis of patient-specific factors, and the noncardiac sequelae of DMD place these patients on the higher-risk end of the spectrum.

Future Directions-At this time, the severe noncardiac manifestations of DMD preclude most patients with DMD from being considered candidates for a heart transplant. If new therapies are able to reduce the noncardiac morbidity and mortality in this population, then heart transplantation may become a more realistic option. The role of destination LVAD therapy is continuing to evolve. It is essential to develop criteria for identifying patients with DMD who are most likely to benefit from LVAD placement. This process will involve a multidisciplinary assessment by a care team, including in cardiology, cardiac surgery, anesthesiology, neurology, pulmonology, orthopedic surgery, and physical therapy. The involvement of psychology and the palliative care team is also essential. (For additional details, see the psychosocial care specialty article that is part of this supplement. ${ }^{66}$ ) End-oflife issues related to destination LVAD placement in pediatric and young adult patients, including the inevitable eventual withdrawal of support, require careful consideration and honest discussion before device placement. ${ }^{67}$

\section{Arrhythmias and Device Therapy}

Arrhythmias are an important potential contributor to mortality in DMD. Recent studies reveal the presence of atrial and ventricular premature beats, atrial tachycardia, ventricular couplets, and nonsustained and sustained ventricular tachycardia (VT) in these patients. ${ }^{68-70}$ Decreased EF is strongly correlated with the incidence of nonsustained and sustained VT. Nonsustained VT occurs in $\$ 30 \%$ of patients with DMD and an LVEF of $<35 \%$. In evaluating the usefulness of arrhythmias predicting sudden death in DMD, LVEF was the only predictor of mortality, and ventricular arrhythmias were not. ${ }^{68-70}$ The benefit of an implantable cardioverter defibrillator (ICD) has not been established for patients with DMD. However, an ICD benefit in the adult population (non-DMD) with a reduced LVEF $(<35 \%)$ on maximal medical therapy as a primary prevention strategy has been well established 
through the Sudden Cardiac Death Heart Failure Trial, which revealed that ICD therapy reduced overall mortality by $23 \% .{ }^{71}$ In this context, primary prevention refers to an approach to prevent sudden cardiac death on the basis of predictive factors, whereas secondary prevention refers to the prevention of a second occurrence of resuscitated sudden cardiac death. For patients with DMD who have sustained VT or resuscitated sudden cardiac death, the decision for an ICD implant is straightforward because these are accepted class I indications for use as a secondary prevention.

Clinical Controversy-The dilemma is what to do for patients with DMD who have nonsustained VT and/or an LVEF of $<35 \%$. In the adult heart failure population, the Sudden Cardiac Death Heart Failure Trial $(n=1211$; average age: 58 years) revealed that the benefit outweighed the risk for ICDs in favor of implant among patients with an LVEF of $<35 \%$. ${ }^{71}$ However, it is unknown whether the DMD population, which is younger and has a nonischemic cardiomyopathy, would similarly benefit. In addition, placement of an ICD in patients with DMD may confer a higher risk because of accompanying skeletal muscle and respiratory compromise. Pediatric studies provide little additional guidance. In a 2009 study, Dimas et al ${ }^{72}$ reviewed all patients with idiopathic dilated cardiomyopathy (DCM) seen at Texas Children's Hospital over a 14-year period. The study included 85 patients (median age: 3.8 years) with a median LVEF of $23 \%$. In that cohort, 1 sudden cardiac death event occurred. In 2012, Pahl et al ${ }^{73}$ conducted a similar review of 1803 patients with DCM (mean age: 5.3 years) in patients enrolled in the Pediatric Cardiomyopathy Registry. At most, a 3\% 5-year incidence of sudden death occurred, and EF and sudden death were not correlated. Other case reports and small case series include small numbers of patients with DMD who have received ICDs. ${ }^{28,70,74}$ The majority of patients with ICDs in these reports had no documented sustained ventricular arrhythmias, and only 1 patient received appropriate shocks (treatment of VT or ventricular fibrillation); the patient died of ventricular fibrillation despite multiple appropriate device discharges. ${ }^{28}$

Future Directions-A better understanding of the risks and benefits is necessary before recommending ICDs as a primary prevention in patients with DMD. An international registry is currently enrolling patients to evaluate the incidence of arrhythmias and ICD use specifically among the DMD population (principal investigator: Kertesz and co-workers ${ }^{75}$; Nationwide Children's Hospital). The risk of ICD placement in children and adolescents is not insignificant, with $21 \%$ of youth receiving inappropriate shocks (shocks for rhythms that should not be defibrillated) and $12 \%$ of youth having complications within 30 days of implantation. Unfortunately, there may be an increased risk of ICD placement in the DMD population because of anesthesia risks, respiratory compromise, and contractures.

\section{Therapies Directly Targeting Dystrophin Deficiency}

In September 2016, the Food and Drug Administration granted accelerated approval for the first drug that was used to directly target the underlying dystrophin deficiency in DMD. Eteplirsen is an exon-skipping drug with the potential to improve skeletal myopathy in a subset of patients with DMD. Animal studies, however, reveal that this class of exonskipping medications (phosphorodiamidate morpholino oligimers) is significantly less efficacious in the heart compared with in the skeletal muscle. ${ }^{76-78}$ The cardiac effects of 
eteplirsen are unknown in humans. It is hoped that eteplirsen approval will accelerate the development of similar disease-targeting medications. However, even if treatments are found to ameliorate the skeletal myopathy, mortality will not be affected unless improved cardiac treatments are discovered. Cardiomyopathy has the potential of limiting the overall functional benefit of the new therapies in which the skeletal muscle is targeted. It is essential that research includes an analysis of novel therapies on cardiac function.

\title{
FUNDING:
}

Supported in part by Cooperative Agreement NU38OT000167, funded by the Centers for Disease Control and Prevention.

POTENTIAL CONFLICT OF INTEREST: Northwestern University receives grant support on behalf of Dr McNally from Solid Biosciences. In addition, Dr McNally is a consultant to Exonics and Invitae. She is a founder of Ikaika Therapeutics and holds a patent relevant to muscular dystrophies; Dr Wagner has received an honorarium from FibroGen, Hoffmann-La Roche, and Wave Life Sciences; the other authors have indicated they have no potential conflicts of interest to disclose.

\author{
ABBREVIATIONS \\ ACEi angiotensin-converting enzyme inhibitor \\ ARB angiotensin receptor blocker \\ CMRI cardiac MRI \\ DMD Duchenne muscular dystrophy \\ EF ejection fraction \\ ICD implantable cardioverter defibrillator \\ LGE late gadolinium enhancement \\ LVAD left ventricular assist device \\ LVEF left ventricular ejection fraction \\ VT ventricular tachycardia
}

\section{REFERENCES}

1. Grady RM, Teng H, Nichol MC, Cunningham JC, Wilkinson RS, Sanes JR. Skeletal and cardiac myopathies in mice lacking utrophin and dystrophin: a model for Duchenne muscular dystrophy. Cell. 1997;90(4):729-738 [PubMed: 9288752]

2. Hainsey TA, Senapati S, Kuhn DE, Rafael JA. Cardiomyopathic features associated with muscular dystrophy are independent of dystrophin absence in cardiovasculature. Neuromuscul Disord. 2003;13(4):294-302 [PubMed: 12868498]

3. Biggar WD. Duchenne muscular dystrophy. Pediatr Rev. 2006;27(3):83-88 [PubMed: 16510548]

4. Gilroy J, Cahalan JL, Berman R, Newman M. Cardiac and pulmonary complications in Duchenne's progressive muscular dystrophy. Circulation. 1963;27(4, pt 1):484-493 [PubMed: 13947981]

5. Muntoni F Cardiac complications of childhood myopathies. J Child Neurol. 2003;18(3):191-202 [PubMed: 12731645] 
6. de Kermadec JM, Bécane HM, Chénard A, Tertrain F, Weiss Y. Prevalence of left ventricular systolic dysfunction in Duchenne muscular dystrophy: an echocardiographic study. Am Heart J. 1994;127(3):618-623 [PubMed: 8122611]

7. Eagle M, Baudouin SV, Chandler C, Giddings DR, Bullock R, Bushby K. Survival in Duchenne muscular dystrophy: improvements in life expectancy since 1967 and the impact of home nocturnal ventilation. Neuromuscul Disord. 2002;12(10):926-929 [PubMed: 12467747]

8. Birnkrant DJ, Bushby K, Bann CM, et al.; DMD Care Considerations Working Group. Diagnosis and management of Duchenne muscular dystrophy, part 2: respiratory, cardiac, bone health, and orthopaedic management. Lancet Neurol. 2018;17(4):347-361 [PubMed: 29395990]

9. Jefferies JL, Eidem BW, Belmont JW, et al. Genetic predictors and remodeling of dilated cardiomyopathy in muscular dystrophy. Circulation. 2005;112(18):2799-2804 [PubMed: 16246949]

10. Ogata H, Ishikawa Y, Ishikawa Y, Minami R. Beneficial effects of beta-blockers and angiotensinconverting enzyme inhibitors in Duchenne muscular dystrophy. J Cardiol. 2009;53(1):72-78 [PubMed: 19167641]

11. Viollet L, Thrush PT, Flanigan KM, Mendell JR, Allen HD. Effects of angiotensin-converting enzyme inhibitors and/or beta blockers on the cardiomyopathy in Duchenne muscular dystrophy. Am J Cardiol. 2012;110(1):98-102 [PubMed: 22463839]

12. Spurney C, Shimizu R, Morgenroth LP, Kolski H, Gordish-Dressman H, Clemens PR; CINRG Investigators. Cooperative International Neuromuscular Research Group Duchenne Natural History Study demonstrates insufficient diagnosis and treatment of cardiomyopathy in Duchenne muscular dystrophy. Muscle Nerve. 2014;50(2):250-256 [PubMed: 24395289]

13. Bushby K, Finkel R, Birnkrant DJ, et al.; DMD Care Considerations Working Group. Diagnosis and management of Duchenne muscular dystrophy, part 1: diagnosis, and pharmacological and psychosocial management. Lancet Neurol. 2010;9(1):77-93 [PubMed: 19945913]

14. Kamdar F, Garry DJ. Dystrophin-deficient cardiomyopathy. JAm Coll Cardiol. 2016;67(21):25332546 [PubMed: 27230049]

15. McNally EM, Kaltman JR, Benson DW, et al.; Working Group of the National Heart, Lung, and Blood Institute; Parent Project Muscular Dystrophy. Contemporary cardiac issues in Duchenne muscular dystrophy. Working Group of the National Heart, Lung, and Blood Institute in collaboration with Parent Project Muscular Dystrophy [published correction appears in Circulation. 2015;131(25):e539]. Circulation. 2015;131 (18):1590-1598 [PubMed: 25940966]

16. Mavrogeni S, Markousis-Mavrogenis G, Papavasiliou A, Kolovou G. Cardiac involvement in Duchenne and Becker muscular dystrophy. World J Cardiol. 2015;7(7):410-414 [PubMed: 26225202]

17. van Bockel EA, Lind JS, Zijlstra JG, et al. Cardiac assessment of patients with late stage Duchenne muscular dystrophy. Neth Heart J. 2009;17(6):232-237 [PubMed: 19789685]

18. Spurney CF, McCaffrey FM, Cnaan A, et al. Feasibility and reproducibility of echocardiographic measures in children with muscular dystrophies. J Am Soc Echocardiogr. 2015;28(8):999-1008 [PubMed: 25906753]

19. Soslow JH, Markham LW, Saville B, Xu M, Damon BM, Parra D. Left ventricular function by echocardiography correlates poorly with cardiac MRI measures in Duchenne muscular dystrophy. J Cardiovasc Magn Reson. 2014;16(suppl 1):P306

20. Brunklaus A, Parish E, Muntoni F, et al. The value of cardiac MRI versus echocardiography in the pre-operative assessment of patients with Duchenne muscular dystrophy. Eur J Paediatr Neurol. 2015;19(4):395-401 [PubMed: 25843299]

21. Buddhe S, Lewin M, Olson A, Ferguson M, Soriano BD. Comparison of left ventricular function assessment between echocardiography and MRI in Duchenne muscular dystrophy. Pediatr Radiol. 2016;46(10):1399-1408 [PubMed: 27173979]

22. Pearson CM. Muscular dystrophy. Review and recent observations. Am J Med 1963;35:632-645 [PubMed: 14076017]

23. Frankel KA, Rosser RJ. The pathology of the heart in progressive muscular dystrophy: epimyocardial fibrosis. Hum Pathol. 1976;7(4):375-386 [PubMed: 939536] 
24. Verhaert D, Richards K, Rafael-Fortney JA, Raman SV. Cardiac involvement in patients with muscular dystrophies: magnetic resonance imaging phenotype and genotypic considerations. Circ Cardiovasc Imaging. 2011;4(1):67-76 [PubMed: 21245364]

25. Silva MC, Meira ZM, Gurgel Giannetti J, et al. Myocardial delayed enhancement by magnetic resonance imaging in patients with muscular dystrophy. J Am Coll Cardiol. 2007;49(18):18741879 [PubMed: 17481447]

26. Puchalski MD, Williams RV, Askovich B, et al. Late gadolinium enhancement: precursor to cardiomyopathy in Duchenne muscular dystrophy? Int J Cardiovasc Imaging. 2009;25(1):57-63 [PubMed: 18686011]

27. Hor KN, Taylor MD, Al-Khalidi HR, et al. Prevalence and distribution of late gadolinium enhancement in a large population of patients with Duchenne muscular dystrophy: effect of age and left ventricular systolic function. J Cardiovasc Magn Reson. 2013;15:107 [PubMed: 24359596]

28. Menon SC, Etheridge SP, Liesemer KN, et al. Predictive value of myocardial delayed enhancement in Duchenne muscular dystrophy. Pediatr Cardiol. 2014;35(7):1279-1285 [PubMed: 24830760]

29. Florian A, Ludwig A, Engelen M, et al. Left ventricular systolic function and the pattern of lategadolinium-enhancement independently and additively predict adverse cardiac events in muscular dystrophy patients. J Cardiovasc Magn Reson. 2014;16:81 [PubMed: 25315351]

30. Ashford MW Jr, Liu W, Lin SJ, et al. Occult cardiac contractile dysfunction in dystrophin-deficient children revealed by cardiac magnetic resonance strain imaging. Circulation. 2005;112(16):24622467 [PubMed: 16216964]

31. Hor KN, Gottliebson WM, Carson C, et al. Comparison of magnetic resonance feature tracking for strain calculation with harmonic phase imaging analysis. JACC Cardiovasc Imaging. 2010;3(2): 144-151 [PubMed: 20159640]

32. Hor KN, Kissoon N, Mazur W, et al. Regional circumferential strain is a biomarker for disease severity in Duchenne muscular dystrophy heart disease: a cross-sectional study. Pediatr Cardiol. 2015;36(1):111-119 [PubMed: 25085262]

33. Schuster A, Stahnke VC, Unterberg-Buchwald C, et al. Cardiovascular magnetic resonance featuretracking assessment of myocardial mechanics: intervendor agreement and considerations regarding reproducibility. Clin Radiol. 2015;70(9):989-998 [PubMed: 26139384]

34. Hor KN, Wansapura J, Markham LW, et al. Circumferential strain analysis identifies strata of cardiomyopathy in Duchenne muscular dystrophy: a cardiac magnetic resonance tagging study. $\mathrm{J}$ Am Coll Cardiol. 2009;53(14):1204-1210 [PubMed: 19341862]

35. Kanda T, Ishii K, Kawaguchi H,Kitajima K, Takenaka D. Highsignal intensity in the dentate nucleus and globus pallidus on unenhanced T1-weighted MR images: relationship with increasing cumulative dose of a gadolinium-based contrast material. Radiology. 2014;270(3):834-841 [PubMed: 24475844]

36. McDonald RJ, McDonald JS, Kallmes DF, et al. Intracranial gadolinium deposition after contrastenhanced MR imaging. Radiology. 2015;275(3):772-782 [PubMed: 25742194]

37. Gulani V, Calamante F, Shellock FG, Kanal E, Reeder SB; International Society for Magnetic Resonance in Medicine. Gadolinium deposition in the brain: summary of evidence and recommendations. Lancet Neurol. 2017;16(7):564-570 [PubMed: 28653648]

38. Soslow JH, Damon BM, Saville BR, et al. Evaluation of post-contrast myocardial t1 in Duchenne muscular dystrophy using cardiac magnetic resonance imaging. Pediatr Cardiol. 2015;36(1):49-56 [PubMed: 25070387]

39. Starc JJ, Moore RA, Rattan MS, et al. Elevated myocardial extracellular volume fraction in Duchenne muscular dystrophy. Pediatr Cardiol. 2017;38(7):1485-1492 [PubMed: 28762167]

40. Olivieri LJ, Kellman P, McCarter RJ, Cross RR, Hansen MS, Spurney CF. Native T1 values identify myocardial changes and stratify disease severity in patients with Duchenne muscular dystrophy. J Cardiovasc Magn Reson. 2016;18(1):72 [PubMed: 27788681]

41. Feingold B, Mahle WT, Auerbach S, et al.; American Heart Association Pediatric Heart Failure Committee of the Council on Cardiovascular Disease in the Young; Council on Clinical Cardiology; Council on Cardiovascular Radiology and Intervention; Council on Functional Genomics and Translational Biology; Stroke Council. Management of cardiac involvement 
associated with neuromuscular diseases: a scientific statement from the American Heart Association. Circulation. 2017;136(13):e200-e231 [PubMed: 28838934]

42. Raman SV, Hor KN, Mazur W, et al. Eplerenone for early cardiomyopathy in Duchenne muscular dystrophy: a randomised, double-blind, placebo-controlled trial. Lancet Neurol. 2015;14(2):153161 [PubMed: 25554404]

43. Raman SV, Hor KN, Mazur W, et al. Eplerenone for early cardiomyopathy in Duchenne muscular dystrophy: results of a two-year open-label extension trial. Orphanet J Rare Dis. 2017;12(1):39 [PubMed: 28219442]

44. Duboc D, Meune C, Lerebours G, Devaux JY, Vaksmann G, Bécane HM. Effect of perindopril on the onset and progression of left ventricular dysfunction in Duchenne muscular dystrophy. $\mathrm{J}$ Am Coll Cardiol. 2005;45(6):855-857 [PubMed: 15766818]

45. Duboc D, Meune C, Pierre B, et al. Perindopril preventive treatment on mortality in Duchenne muscular dystrophy: 10 years' follow-up. Am Heart J. 2007;154(3):596-602 [PubMed: 17719312]

46. Yancy CW, Jessup M, Bozkurt B, et al.; Writing Committee Members. 2016 ACC/AHA/HFSA focused update on new pharmacological therapy for heart failure: an update of the 2013 ACCF/AHA guideline for the management of heart failure: a report of the American College of Cardiology/American Heart Association Task Force on Clinical Practice Guidelines and the Heart Failure Society of America. Circulation. 2016;134(13):e282-e293 [PubMed: 27208050]

47. Owens AT, Brozena SC, Jessup M. New management strategies in heart failure. Circ Res. 2016;118(3):480-495 [PubMed: 26846642]

48. McMurray JJ, Packer M, Desai AS, et al.; PARADIGM-HF Investigators and Committees. Angiotensin-neprilysin inhibition versus enalapril in heart failure. N Engl J Med. 2014;371 (11): 993-1004 [PubMed: 25176015]

49. Swedberg K, Komajda M, Böhm M, et al.; SHIFT Investigators. Ivabradine and outcomes in chronic heart failure (SHIFT): a randomised placebo-controlled study [published correction appears in Lancet. 2010;376(9757):1988]. Lancet. 2010;376(9744):875-885 [PubMed: 20801500]

50. Yancy CW, Jessup M, Bozkurt B, et al.; American College of Cardiology Foundation; American Heart Association Task Force on Practice Guidelines. 2013 ACCF/AHA guideline for the management of heart failure: a report of the American College of Cardiology Foundation/ American Heart Association Task Force on Practice Guidelines. J Am Coll Cardiol. 2013;62(16):e147-e239 [PubMed: 23747642]

51. Canter CE, Shaddy RE, Bernstein D,et al.; American Heart Association Council on Cardiovascular Disease in the Young; American Heart Association Council on Clinical Cardiology; American Heart Association Council on Cardiovascular Nursing; American Heart Association Council on Cardiovascular Surgeryand Anesthesia; Quality of Care and Outcomes Research Interdisciplinary Working Group. Indications for heart transplantation in pediatric heart disease: a scientific statement from the American Heart Association Council on Cardiovascular Disease in the Young; the Councils on Clinical Cardiology, Cardiovascular Nursing, and Cardiovascular Surgery and Anesthesia; and the Quality of Care and Outcomes Research Interdisciplinary Working Group [published correction appears in Circulation. 2007;115(13):e385]. Circulation. 2007;115(5):658676 [PubMed: 17261651]

52. Rees W, Schüler S, Hummel M, Hetzer R. Heart transplantation in patients with muscular dystrophy associated with end-stage cardiomyopathy. J Heart Lung Transplant. 1993;12(5):804807 [PubMed: 8241218]

53. Wu RS, Gupta S, Brown RN, et al. Clinical outcomes after cardiac transplantation in muscular dystrophy patients. J Heart Lung Transplant. 2010;29(4):432-438 [PubMed: 19864165]

54. Connuck DM, Sleeper LA, Colan SD, et al.; Pediatric Cardiomyopathy Registry Study Group. Characteristics and outcomes of cardiomyopathy in children with Duchenne or Becker muscular dystrophy: a comparative study from the Pediatric Cardiomyopathy Registry. Am Heart J. 2008;155(6):998-1005 [PubMed: 18513510]

55. Rose EA, Gelijns AC, Moskowitz AJ, et al.; Randomized Evaluation of Mechanical Assistance for the Treatment of Congestive Heart Failure (REMATCH) Study Group. Long-term use of a left ventricular assist device for end-stage heart failure. N Engl J Med. 2001;345(20):1435-1443 [PubMed: 11794191] 
56. Kirklin JK, Naftel DC, Pagani FD, et al. Sixth INTERMACS annual report: a 10,000-patient database [published correction appears in J Heart Lung Transplant. 2015;34(10):1356]. J Heart Lung Transplant. 2014;33(6):555-564 [PubMed: 24856259]

57. Kirklin JK, Naftel DC, Pagani FD, et al. Seventh INTERMACS annual report: 15,000 patients and counting. J Heart Lung Transplant. 2015;34(12):1495-1504 [PubMed: 26520247]

58. Villa CR, Lorts A. Cardiac destination therapy in pediatrics - are we there yet? Pediatr Transplant. 2016;20(6):738-739 [PubMed: 27453068]

59. Ryan TD, Jefferies JL, Sawnani H, et al. Implantation of the HeartMate II and HeartWare left ventricular assist devices in patients with Duchenne muscular dystrophy: lessons learned from the first applications. ASAIO J. 2014;60(2):246-248 [PubMed: 24577373]

60. Iodice F, Testa G, Averardi M,Brancaccio G, Amodeo A, Cogo P. Implantation of a left ventricular assist device as a destination therapy in Duchenne muscular dystrophy patients with end stage cardiac failure: management and lessons learned. Neuromuscul Disord. 2015;25(1):19-23 [PubMed: 25444433]

61. Perri G, Filippelli S, Adorisio R, et al. Left ventricular assist device as destination therapy in cardiac end-stage dystrophinopathies: midterm results. J Thorac Cardiovasc Surg. 2017;153(3): 669-674 [PubMed: 27692952]

62. Stoller D, Araj F, Amin A, et al. Implantation of a left ventricular assist device to provide longterm support for end-stage Duchenne muscular dystrophy-associated cardiomyopathy. ESC Heart Fail. 2017;4(3):379-383 [PubMed: 28772036]

63. Arnold SV, Jones PG, Allen LA, et al. Frequency of poor outcome (death or poor quality of life) after left ventricular assist device for destination therapy: results from the INTERMACS Registry. Circ Heart Fail. 2016;9(8):e002800 [PubMed: 27507111]

64. Lietz K, Long JW, Kfoury AG, et al. Outcomes of left ventricular assist device implantation as destination therapy in the post-REMATCH era: implications for patient selection. Circulation. 2007;116(5):497-505 [PubMed: 17638928]

65. Flint KM, Matlock DD, Sundareswaran KS, et al. Pre-operative health status and outcomes after continuous-flow left ventricular assist device implantation. J Heart Lung Transplant. 2013;32(12): 1249-1254 [PubMed: 24119729]

66. Colvin MK, Poysky J, Kinnett K, et al. Psychosocial management of the patient with Duchenne muscular dystrophy. Pediatrics. 2018; 142(suppl 2):e201 80333L

67. Char DS, Lee SS, Ikoku AA, Rosenthal D, Magnus D. Can Destination Therapy be implemented in children with heart failure? A study of provider perceptions. Pediatr Transplant. 2016;20(6):819824 [PubMed: 27357389]

68. Corrado G, Lissoni A, Beretta S, et al. Prognostic value of electrocardiograms, ventricular late potentials, ventricular arrhythmias, and left ventricular systolic dysfunction in patients with Duchenne muscular dystrophy. Am J Cardiol. 2002;89(7):838-841 [PubMed: 11909570]

69. Villa CR, Czosek RJ, Ahmed H, et al. Ambulatory monitoring and arrhythmic outcomes in pediatric and adolescent patients with Duchenne muscular dystrophy. J Am Heart Assoc. 2015;5(1):e002620 [PubMed: 26722125]

70. Chiang DY, Allen HD, Kim JJ, et al. Relation of cardiac dysfunction to rhythm abnormalities in patients with Duchenne or Becker muscular dystrophies. Am J Cardiol. 2016;117(8):1349-1354 [PubMed: 26952271]

71. Bardy GH, Lee KL, Mark DB, et al.; Sudden Cardiac Death in Heart Failure Trial (SCD-HeFT) Investigators. Amiodarone or an implantable cardioverter-deflbrillator for congestive heart failure. N Engl J Med. 2005;352(3):225-237 [PubMed: 15659722]

72. Dimas VV, Denfield SW, Friedman RA, et al. Frequency of cardiac death in children with idiopathic dilated cardiomyopathy. Am J Cardiol. 2009;104(11):1574-1577 [PubMed: 19932795]

73. Pahl E, Sleeper LA, Canter CE, et al.; Pediatric Cardiomyopathy Registry Investigators. Incidence of and risk factors for sudden cardiac death in children with dilated cardiomyopathy: a report from the Pediatric Cardiomyopathy Registry. J Am Coll Cardiol. 2012;59(6):607-615 [PubMed: 22300696] 
74. Shah AM, Jefferies JL, Rossano JW, Decker JA, Cannon BC,Kim JJ. Electrocardiographic abnormalities and arrhythmia are strongly associated with the development of cardiomyopathy in muscular dystrophy. Heart Rhythm. 2010;7(10):1484-1488 [PubMed: 20601155]

75. Berul CI, Van Hare GF, Kertesz NJ, et al. Results of a multicenter retrospective implantable cardioverter-deflbrillator registry of pediatric and congenital heart disease patients. J Am Coll Cardiol. 2008;51 (17):1685-1691 [PubMed: 18436121]

76. Yokota T, Lu QL, Partridge T, et al. Efficacy of systemic morpholino exon-skipping in Duchenne dystrophy dogs. Ann Neurol. 2009;65(6):667-676 [PubMed: 19288467]

77. Alter J, Lou F, Rabinowitz A, et al. Systemic delivery of morpholino oligonucleotide restores dystrophin expression bodywide and improves dystrophic pathology. Nat Med. 2006;12(2):175177 [PubMed: 16444267]

78. Wu B, Xiao B, Cloer C, et al. One-year treatment of morpholino antisense oligomer improves skeletal and cardiac muscle functions in dystrophic mdx mice. Mol Ther. 2011;19(3):576-583 [PubMed: 21179007] 


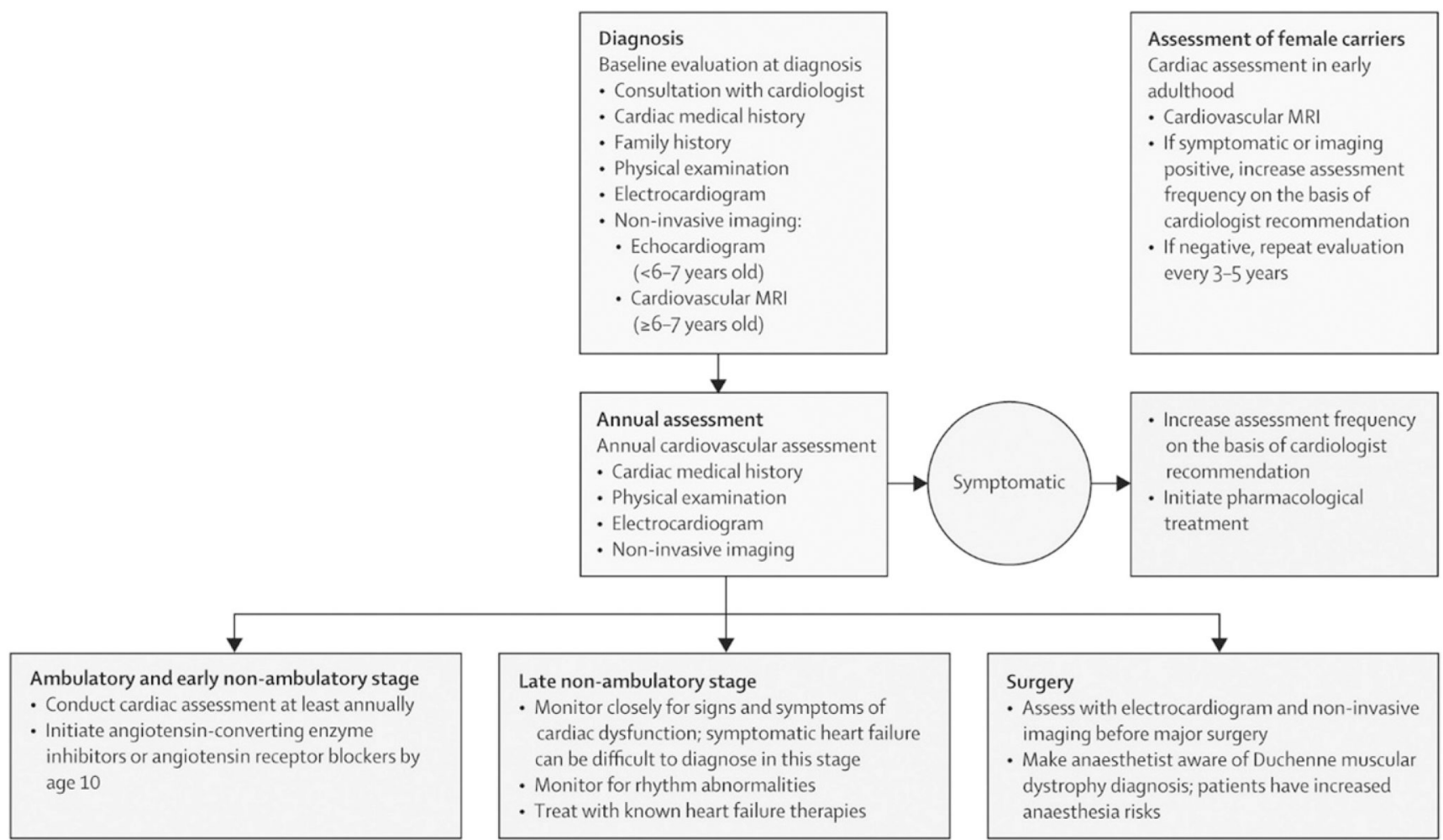

FIGURE 1.

Cardiac monitoring, diagnosis, and treatment algorithm for patients with DMD. In this figure, the process of monitoring, diagnosing, and treating cardiac issues in patients with DMD is illustrated. 